\title{
Transient elastography with the $X L$ probe rapidly identifies patients with nonhepatic ascites
}

This article was published in the following Dove Press journal:

Hepatic Medicine: Evidence and Research

27 April 2012

Number of times this article has been viewed

\begin{abstract}
Anna Kohlhaas'
Esteban Durango'

Gunda Millonig'

Cecile Bastard ${ }^{2}$

Laurent Sandrin ${ }^{2}$

Mohammad Golriz ${ }^{3}$

Arianeb $\mathrm{Mehrabi}^{3}$

Markus W Büchler ${ }^{3}$

Helmut Karl Seitz'

Sebastian Mueller'

'Department of Medicine and Center for Alcohol Research, Liver Disease and Nutrition, Salem Medical Center, University of Heidelberg, Heidelberg, Germany; ${ }^{2}$ Department of Research and Development, Echosens, Paris, France; ${ }^{3}$ Department of General, Visceral and Transplantation Surgery, University of Heidelberg, Heidelberg, Germany
\end{abstract}

Correspondence: Sebastian Mueller Department of Internal Medicine, Salem Medical Center, University of Heidelberg, Zeppelinstrasse II-33, Heidelberg 6912I, Germany

Tel +6221483210

Fax +62 2I 484494

Email sebastian.mueller@urz.uniheidelberg.de
Background: In contrast with other elastographic techniques, ascites is considered an exclusion criterion for assessment of fibrosis stage by transient elastography. However, a normal liver stiffness could rule out hepatic causes of ascites at an early stage. The aim of the present study was to determine whether liver stiffness can be generally determined by transient elastography through an ascites layer, to determine whether the ascites-mediated increase in intra-abdominal pressure affects liver stiffness, and to provide initial data from a pilot cohort of patients with various causes of ascites.

Methods and results: Using the XL probe in an artificial ascites model, we demonstrated (copolymer phantoms surrounded by water) that a transient elastography-generated shear wave allows accurate determination of phantom stiffness up to a water lamella of $20 \mathrm{~mm}$. We next showed in an animal ascites model that increased intra-abdominal pressure does not affect liver stiffness. Liver stiffness was then determined in 24 consecutive patients with ascites due to hepatic $(n=18)$ or nonhepatic $(n=6)$ causes. The cause of ascites was eventually clarified using routine clinical, imaging, laboratory, and other tools. Valid $(75 \%)$ or acceptable $(25 \%)$ liver stiffness data could be obtained in 23 patients (95.8\%) with ascites up to an ascites lamella of $39 \mathrm{~mm}$. The six patients (25\%) with nonhepatic causes of ascites (eg, pancreatitis, peritoneal carcinomatosis) had a significantly lower liver stiffness $(<8 \mathrm{kPa})$ as compared with the remaining patients with hepatic ascites $(>30 \mathrm{kPa})$. Mean liver stiffness was $5.4 \mathrm{kPa} \pm 1.3$ versus $66.2 \pm 13.3 \mathrm{kPa}$.

Conclusion: In conclusion, the presence of ascites and increased intra-abdominal pressure does not alter underlying liver stiffness as determined by transient elastography. We suggest that, using the XL probe, transient elastography can be used first-line to identify patients with nonhepatic ascites at an early stage.

Keywords: ascites, liver stiffness, transient elastography, liver cirrhosis, noncirrhotic ascites, congestion, peritoneal carcinomatosis, intra-abdominal pressure, alcoholic liver disease

\section{Introduction}

Diagnosis of the underlying cause of ascites is still a difficult challenge. The disease spectrum potentially leading to ascites is broad, and ranges from various liver diseases, such as cirrhosis, liver cancer, and hepatic venous occlusion, to nonhepatic entities like pancreatitis, tuberculosis, serositis, portal vein thrombosis, and peritoneal carcinomatosis. Although decompensated liver cirrhosis has been established as the major cause of ascites in about $80 \%$ of cases, ${ }^{1}$ there remains a significant number of patients who often undergo long and intensive clinical examinations before a nonhepatic cause can be established.

At present, clinical tools to rule out liver cirrhosis unfortunately are not specific and sensitive enough to make a precise diagnosis. About $40 \%$ of patients with cirrhosis 
are asymptomatic and routine laboratory tests are normal. ${ }^{2,3}$ Likewise, modern ultrasound devices and other imaging techniques allow the diagnosis of cirrhosis to be established only in the presence of so-called definite signs of cirrhosis. These signs include a nodular aspect of the liver surface or a recanalized umbilical vein but not an enlarged spleen. ${ }^{4}$ The diagnostic procedure is further complicated in some patients because ascites can cause sparseness of the hepatic veins in imaging studies that may be suggestive of cirrhosis. Although the serum-ascites albumin gradient has been an improvement as compared with the old exudate-transudate concept in discriminating ascites due to portal hypertension from other causes, this parameter can be modulated by superinfections of ascites. ${ }^{5}$

Liver biopsy, considered the gold standard for assessing hepatic fibrosis or cirrhosis, is invasive with potential complications ${ }^{6}$ and has limitations because of well-known interobserver variability and sampling errors of up to $30 \%$. $^{7-11}$

Liver stiffness as determined by ultrasound-based elastographic techniques has been recently introduced as a novel and noninvasive surrogate parameter for liver cirrhosis that could facilitate identification of ascites due to hepatic reasons. ${ }^{12,13}$ Indeed, two recent reports suggest that acoustic radiation force impulse elastography ${ }^{14}$ and real-time tissue elastography ${ }^{15}$ are both able to measure liver stiffness in livers surround by ascites and can discriminate between cirrhotic and noncirrhotic causes of ascites. Supersonic shear imaging is another attractive ultrasound-based technique that enables liver stiffness measurements through ascites layers and provides additional B-mode information. ${ }^{16}$

In contrast, ascites is considered an exclusion criterion for transient elastography $\left(\right.$ FibroScan $\left.^{\circledR}\right)$ which is the most widely explored elastographic technique for assessment of liver cirrhosis. ${ }^{17}$ Moreover, patients with ascites have been excluded from studies that use the recently introduced more powerful XL probe specifically developed for obese patients. ${ }^{18}$ Using this probe, we demonstrate here that liver stiffness can be determined by transient elastography and remains unaffected by the ascites lamella and increased intra-abdominal pressure. Finally, we show that transient elastography allows us to identify patients with nonhepatic ascites.

\section{Materials and methods}

\section{Liver stiffness measured by transient elastography}

Liver stiffness was measured on the day of admission by transient elastography as described recently in detail. ${ }^{17}$ The tip of the probe transducer was placed on the skin between the ribs and the level of the right lobe of the liver. The results are expressed in $\mathrm{kPa}$. The median value was taken as representative. The measurement depth was between $25 \mathrm{~mm}$ and $65 \mathrm{~mm}$ (M probe) or 30-90 $\mathrm{mm}$ (XL probe) below the skin surface. In our study, all patients could be measured with the XL probe except one. Prior paracentesis was required in three cases. For 18 patients (75\%), the generally used valid shot criteria could be reached by the XL probe (interquartile range $<30 \%$ or a success rate $>60 \%$ for at least 10 measurements) using the automatic FibroScan mode. In the remaining six patients (25\%), statistically acceptable data could be obtained with an interquartile range $<50 \%$ and at least three successful measurements.

\section{Ascites phantom model}

In order to test whether ascites fluid per se affects liver stiffness measurements by transient elastography, we used three tissue-mimicking copolymer-in-oil phantoms. The tissue-mimicking phantoms were made of a mixture of styrene-ethylene/butylenestyrene copolymer and mineral oil. A 35-70 $\mu \mathrm{m}$ silica powder was used for acoustic scattering, as described recently. ${ }^{19}$ The phantoms had three different degrees of stiffness $(4.8,11$, and $40 \mathrm{kPa})$ representing various stages of fibrosis (F0, F3, and F4, respectively). The stiffness of these phantoms was first measured without an additional water phase (direct contact of XL probe with phantom). A specifically programmed transient elastography mode allowed us to perform these measurements without applying any pressure on the surface of the phantom. Thus, pressureinduced changes of liver stiffness could be avoided. We then measured liver stiffness of the same three phantoms through a water-filled plastic bag mimicking ascites. The artificial ascites lamella ranged between $20 \mathrm{~mm}$ and $30 \mathrm{~mm}$.

\section{Experimental animals and treatment}

We used three German landrace pigs $(20.3 \pm 2.7 \mathrm{~kg})$ to measure liver stiffness as a function of ascites and intra-abdominal pressure. Details of the standardized narcotic protocol have recently been described elsewhere. ${ }^{20,21}$ Cardiocirculatory parameters, such as central venous and mean arterial pressure, were measured using indwelling catheters in the internal jugular vein and common carotid artery, respectively. A laparoscopic trocar served as a guide for injecting isotonic saline solution as artificial ascites and for measuring the intra-abdominal pressure. Central venous pressure was continuously monitored via a venous catheter. Approval for the experimental procedure was obtained from the German Committee on Animal Care, Regierungspräsidium Karlsruhe 
and the Medical Faculty Ethics Committee, University of Heidelberg. During the experiments, all animals received humane care in compliance with the European Regulations for Animal Experiments and the United States National Research Council's criteria for humane care, as outlined in the Guide for the Care and Use of Laboratory Animals prepared by the National Institution of Health.

\section{Patients}

Twenty-four patients, mean age $65 \pm 12$ years, comprising seven women and 17 men, presenting with ascites at the Salem Medical Center/University of Heidelberg from March 2010 to June 2011 were consecutively enrolled in this pilot study (Table 1). Liver stiffness was measured on the day of admission without knowledge of the underlying disease for the examiner. The cause of ascites could be established by clinical,

Table I Patient characteristics and differences between hepatic and nonhepatic ascites group

\begin{tabular}{|c|c|c|}
\hline Parameter & Cirrhotics & Non cirrhotics \\
\hline Age & $63.9 \pm 12.2$ & $76.0 \pm 6.7$ \\
\hline \multicolumn{3}{|l|}{ Sex, n (\%) } \\
\hline Female & 3 & 4 \\
\hline Male & 15 & 2 \\
\hline Weight (kg) & $77.2 \pm 16.6$ & $68.8 \pm 18.8$ \\
\hline Size $(m)$ & $1.73 \pm 0.07$ & $1.61 \pm 0.07$ \\
\hline BMI $\left(\mathrm{kg} / \mathrm{m}^{2}\right)$ & $25.7 \pm 4.6$ & $26.9 \pm 9.0$ \\
\hline Waist (cm) & $106.2 \pm 13.1$ & $102.5 \pm 16.9$ \\
\hline Hip (cm) & $95.4 \pm 8.8$ & $101.2 \pm 13.0$ \\
\hline Waist/hip ratio & $I .1 I \pm 0.11$ & $1.01 \pm 0.09$ \\
\hline $\begin{array}{l}\text { Skin-capsula distance w/o } \\
\text { pressure }(\mathrm{mm})\end{array}$ & $36.0 \pm 11.9$ & $25.8 \pm 6.2$ \\
\hline $\begin{array}{l}\text { Skin-capsula distance w } \\
\text { pressure }(\mathrm{mm})\end{array}$ & $29.7 \pm 10.8$ & $24.9 \pm 7.1$ \\
\hline Ascites (mm) & $14.5 \pm 9.7$ & $7.7 \pm 5.4$ \\
\hline $\begin{array}{l}\text { Liver size, middle axillar } \\
\text { line }(\mathrm{cm})\end{array}$ & $13.0 \pm 2.7$ & $12.2 \pm 2.2$ \\
\hline Spleen size $(\mathrm{cm})$ & $12.8 \pm 3.8$ & $9.7 \pm 2.4$ \\
\hline $\begin{array}{l}\text { Liver stiffness }(\mathrm{kPa}) \\
\mathrm{XL} \text { probe }\end{array}$ & $66.2 \pm 13.3$ & $5.4 \pm 1.3$ \\
\hline $\mathrm{IQR}, \mathrm{XL}$ probe & $9.9 \pm 10.6$ & $1.0 \pm 1.0$ \\
\hline IQR/LS ratio (\%) & $0.2 \pm 0.2$ & $0.2 \pm 0.2$ \\
\hline Success rate (\%), XL probe & $70.4 \pm 33.4$ & $93.3 \pm 10.3$ \\
\hline GOT (U/L) & $105.8 \pm 112.6$ & $29.2 \pm 10.6$ \\
\hline GPT (U/L) & $45.6 \pm 36.2$ & $15.3 \pm 7.9$ \\
\hline GGT (U/L) & $366.1 \pm 383.1$ & $59.4 \pm 59.0$ \\
\hline AP (U/l) & $239.5 \pm 154.7$ & $73.0 \pm 13.2$ \\
\hline Bilirubin (mg/dL) & $5.3 \pm 6.0$ & $0.8 \pm 0.7$ \\
\hline Quick (\%) & $65.9 \pm 23.5$ & $95.8 \pm 18.6$ \\
\hline INR & $1.36 \pm 0.28$ & $1.03 \pm 0.12$ \\
\hline Platelets & $247.4 \pm 188.5$ & $271.0 \pm 111.2$ \\
\hline
\end{tabular}

Abbreviations: $L S$, liver stiffness; IQR, interquartile range; $A P$, alkaline phosphatase; GGT, gamma glutamyltransferase; GOT, glutamate oxaloacetate transaminase; GPT, glutamate pyruvate transminase; INR, international normalised ratio. laboratory, ascites, and ultrasound examination in all patients. In most cases with two exceptions, the cirrhosis was recognized by ultrasound using so-called definite signs of cirrhosis, such as nodular aspect of the liver surface and collaterals. In the two remaining cases, liver histology confirmed the presence of cirrhosis. In some cases, additional endoscopic ultrasound, endoscopic retrograde cholangiopancreatography, computed tomography scan, bone marrow puncture, or echocardiography were necessary to confirm the diagnosis of pancreatic cancer, mechanical cholestasis, hepatic metastasis, myelofibrosis, or cardiac insufficiency. Ascites was due to liver disease in 18 cases but unrelated to liver manifestation in six patients. Further details of the underlying causes are shown in Table 2. The study was approved by the Ethics Committee of the University of Heidelberg.

\section{Statistical analysis}

Correlations between laboratory findings and liver stiffness in patients were calculated as bivariate regression analysis for nonparametric variables according to Spearman's correlation or with regard to phantom data according to Pearson's correlation (regression coefficient $\mathrm{r}, \mathrm{r}^{2}, P$ ). Differences were considered statistically significant at $P<0.05$. All statistical analyses were performed using PASW Statistics 18, version 18.0.0 (SPSS Inc, Munich, Germany).

\section{Results \\ Transient elastography ( $X L$ probe) measures liver stiffness despite ascites}

Figure 1A demonstrates successful measurement of liver stiffness using the FibroScan device (left panels shows $M$ and A mode ultrasound, right panel shows elastograph) in a patient with established alcoholic liver cirrhosis (patient 12, Table 1) and ascites. Despite the massive ascites lamella of $39 \mathrm{~mm}$, which is visible in the $\mathrm{M}$ mode graph (arrow), a strong shear wave was observed without diffraction artefacts. The rather high liver stiffness of $55.1 \mathrm{kPa}$ clearly confirmed liver cirrhosis. Figure 1B shows a normal liver stiffness measurement of $6.4 \mathrm{kPa}$ in a patient with ascites due to portal vein thrombosis (patient 5, Table 1). These two example suggested to us that transient elastography with the XL probe could be principally able to measure liver stiffness in the presence of ascites.

\section{Stiffness measurements in a liver- mimicking phantom surrounded by water} We next tested a liver-ascites mimicking copolymer-in-oil phantom surrounded by water to ascertain whether ascites 
Table 2 Etiologies, ascites lamella, and transient elastography parameters of all 24 patients

\begin{tabular}{|c|c|c|c|c|c|c|c|c|c|}
\hline No & Gender & Age & Liver disease & Etiology of ascites & $\begin{array}{l}\text { Ascites lamella } \\
(\mathrm{mm})\end{array}$ & $\begin{array}{l}\text { LS M probe } \\
(\mathrm{kPa})\end{array}$ & IQR & $\begin{array}{l}\text { LS XL Probe } \\
(\mathrm{kPa})\end{array}$ & IQR \\
\hline I & $\mathrm{F}$ & 71 & None & Biliary pancreatitis & 3 & - & & 4.8 & 0.4 \\
\hline 2 & $F$ & 84 & None & $\begin{array}{l}\text { Peritoneal carcinomatosis, } \\
\text { ovarial carcinoma }\end{array}$ & 13 & 8.0 & 2.9 & 4.1 & 0.4 \\
\hline 3 & $\mathrm{~F}$ & 74 & None & $\begin{array}{l}\text { Peritoneal carcinomatosis, } \\
\text { ovarial carcinoma }\end{array}$ & 4 & 8.7 & 1.0 & 4.9 & 0.5 \\
\hline 4 & $\mathrm{~F}$ & 71 & None & $\begin{array}{l}\text { Peritoneal carcinomatosis, } \\
\text { ovarial carcinoma }\end{array}$ & 1 & 6.2 & 1.4 & 5.7 & 3.1 \\
\hline 5 & $M$ & 71 & None & Portal vein thrombosis & II & 6.8 & 0.7 & 5.2 & 0.8 \\
\hline 6 & M & 85 & None & Portal vein thrombosis & 14 & 10.2 & 2.5 & 7.8 & 0.9 \\
\hline 7 & $M$ & 75 & $\begin{array}{l}\text { Cardiaque cirrhosis } \\
\text { and liver congestion }\end{array}$ & $\begin{array}{l}\text { Cardiaque insufficiency, } \\
\text { coronary heart disease }\end{array}$ & 12 & 66.4 & 12.2 & 43.5 & 13.4 \\
\hline 8 & $M$ & 80 & $\begin{array}{l}\text { Cardiaque cirrhosis } \\
\text { and liver congestion }\end{array}$ & $\begin{array}{l}\text { Cardiaque insufficiency, } \\
\text { coronary heart disease }\end{array}$ & 12 & - & & 58.6 & 21.1 \\
\hline 9 & M & 79 & $\begin{array}{l}\alpha I \text { antitrypsin } \\
\text { deficiency }\end{array}$ & Decompensated cirrhosis & 4 & - & & 75.0 & 0.0 \\
\hline 10 & $M$ & 53 & ALD & Decompensated cirrhosis & 32 & - & & 49.7 & 6.3 \\
\hline II & M & 53 & ALD & Decompensated cirrhosis & 11 & 75.0 & 0.0 & 73.5 & 7.2 \\
\hline 12 & M & 60 & ALD & Decompensated cirrhosis & 39 & - & & 72.0 & II.I \\
\hline 13 & M & 46 & ALD & Decompensated cirrhosis & 4 & 72.1 & 3.0 & 75.0 & 5.9 \\
\hline 14 & M & 69 & ALD & Decompensated cirrhosis & 24 & - & & - & \\
\hline 15 & $\mathrm{~F}$ & 51 & ALD & Decompensated cirrhosis & 18 & - & & 75.0 & 0.0 \\
\hline 16 & M & 61 & ALD & Decompensated cirrhosis & 6 & - & & 75.0 & 0.0 \\
\hline 17 & $\mathrm{~F}$ & 55 & ALD & Decompensated cirrhosis & 14 & - & & 75.0 & 0.0 \\
\hline 18 & M & 59 & ALD & Decompensated cirrhosis & 12 & - & & 75.0 & 0.0 \\
\hline 19 & M & 75 & ALD & Decompensated cirrhosis & 12 & 75.0 & 0.0 & 75.0 & 0.0 \\
\hline 20 & $M$ & 46 & ALD & Decompensated cirrhosis & 9 & - & & 75.0 & 0.0 \\
\hline 21 & M & 74 & $\mathrm{HCV}$ & Decompensated cirrhosis & 6 & 67.9 & 26.6 & 70.7 & 22.2 \\
\hline 22 & M & 60 & $\begin{array}{l}\text { Extramedullar } \\
\text { hematopoesis }\end{array}$ & $\begin{array}{l}\text { Portal hypertension, } \\
\text { myelofibrosis }\end{array}$ & 18 & 28.0 & 5.0 & 35.3 & 4.1 \\
\hline 23 & M & 57 & Liver metastasis & $\begin{array}{l}\text { Peritoneal carcinomatosis, } \\
\text { gastric cancer }\end{array}$ & 23 & - & & 72.1 & 20.5 \\
\hline 24 & $\mathrm{~F}$ & 78 & $\begin{array}{l}\text { Liver metastasis and } \\
\text { mechanic cholestasis }\end{array}$ & $\begin{array}{l}\text { Peritoneal carcinomatosis, } \\
\text { pancreas carcinoma }\end{array}$ & 5 & - & & 50.1 & 36.3 \\
\hline
\end{tabular}

Note: Patients are listed according to LS values in ascending order.

Abbreviations: ALD, alcoholic liver disease; $\mathrm{HCV}$, hepatitis $\mathrm{C}$ virus.

disturbs the physical measurement of liver stiffness by transient elastography. All phantoms had three different degrees of stiffness $(4.8,11$, and $40 \mathrm{kPa})$ representing various stages of fibrosis (F0, F3, and F4, respectively). ${ }^{19}$ Figure 2 shows the elastographs and $\mathrm{M}$ mode results of two representative measurements using the $4.8 \mathrm{kPa}$ and $40 \mathrm{kPa}$ phantoms and an approximately $20 \mathrm{~mm}$ water lamella between the XL probe and phantom. A clear shear wave formation can be seen despite the presence of water, which corresponded well with the phantom stiffness obtained without ascites. In fact, using Pearson's correlation analysis, stiffness measurements with and without surrounding water correlated well $(0.87, P<0.01)$ for the three phantoms used. These studies also show that probe positioning, namely angulation, towards the phantom is critical, as has been shown for transient elastography in general. ${ }^{17} \mathrm{~A}$ strict perpendicular position of the probe is required to prevent overestimation of stiffness. We also sometimes observed diffractions and reflections arising from the novel borders generated by water (water-phantom, water-wall of plastic bag) that could alter the shear wave through superposition. The maximum difference in all our experiments between conditions with and without ascites never exceeded $30 \%$, with an average of $16 \%$. Taken together, our phantom studies indicate that a shear wave can be generated in a solid liver-mimicking phantom through a liquid phase that corresponds well with the stiffness obtained under conditions without surrounding water.

\section{Ascites with elevated intra-abdominal pressure do not increase liver stiffness}

We next tested the hypothesis that increased intra-abdominal pressure affects liver stiffness. To study the influence of 
A

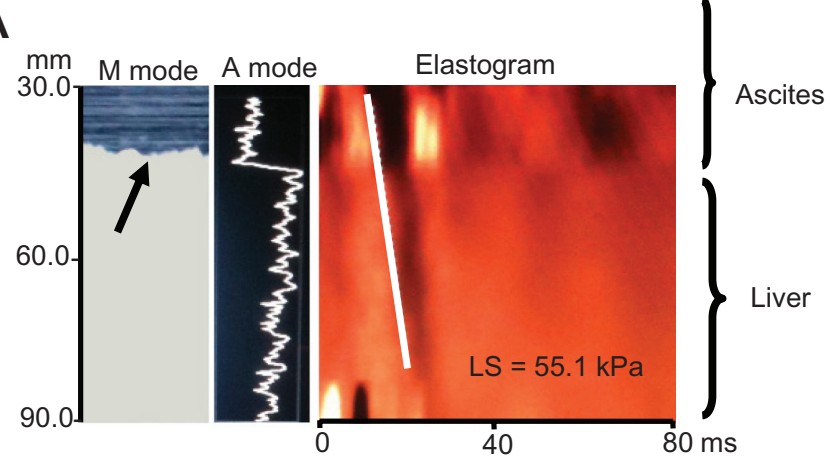

B

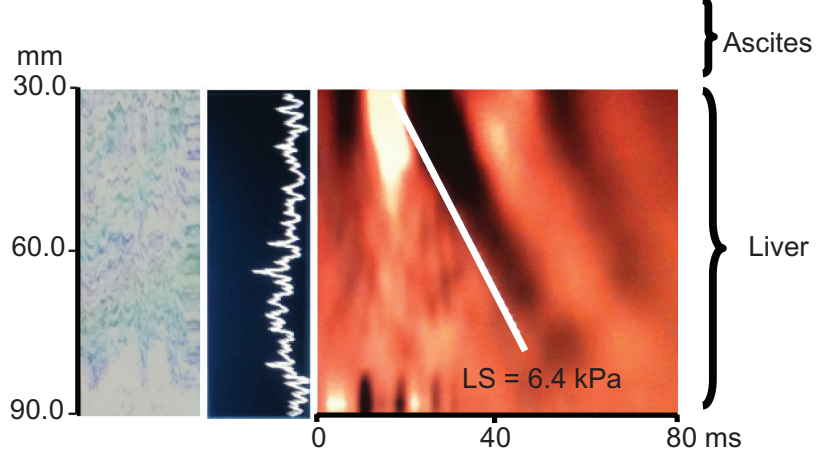

Figure I Example elastographs of two patients with hepatic and nonhepatic ascites (A) Results of $M$ and $A$ ultrasound mode and elastogram in a patient with alcoholic liver cirrhosis and a massive ascites lamella of $39 \mathrm{~mm}$ using the $X \mathrm{~L}$ probe (patient 12 , Table I). Despite ascites which can be seen in the $M$ mode graph (arrow), a strong shear wave is seen corresponding to cirrhotic stiffness values of $55.1 \mathrm{kPa}$. (B) Patient with portal vein thrombosis and a smaller ascites lamella of $1 \mathrm{I} \mathrm{mm}$ (patient 5 , Table 2) shows an almost normal LS measurement of $6.4 \mathrm{kPa}$.

Abbreviation: LS, liver stiffness.

ascites and intra-abdominal pressure of liver stiffness, we established a large animal model of ascites using narcotized German landrace pigs. As shown recently, liver stiffness in pigs is comparable with that in humans. ${ }^{20,21}$ Using a laparoscopic trocar, isotonic saline solution was instilled to generate artificial ascites and to modulate the intra-abdominal pressure. Intra-abdominal pressure and central venous pressure were continuously monitored. One representative example is shown in Figure 3. Intra-abdominal pressure continuously increased over 140 minutes up to $18 \mathrm{mmHg}$. Importantly, liver stiffness does not increase despite a drastically increased intra-abdominal pressure. Central venous pressure also increases over time, probably to prevent collapse of central veins and to maintain the circulation. ${ }^{22}$ We only occasionally observed a transient increase in liver stiffness in cases where increased intra-abdominal pressure caused compression of the low-pressure central veins (central vein, hepatic veins), thus impairing hepatic outflow, as described elsewhere. ${ }^{23}$ In conclusion, ascites and increased intra-abdominal pressure do not affect liver stiffness in the absence of liver congestion.
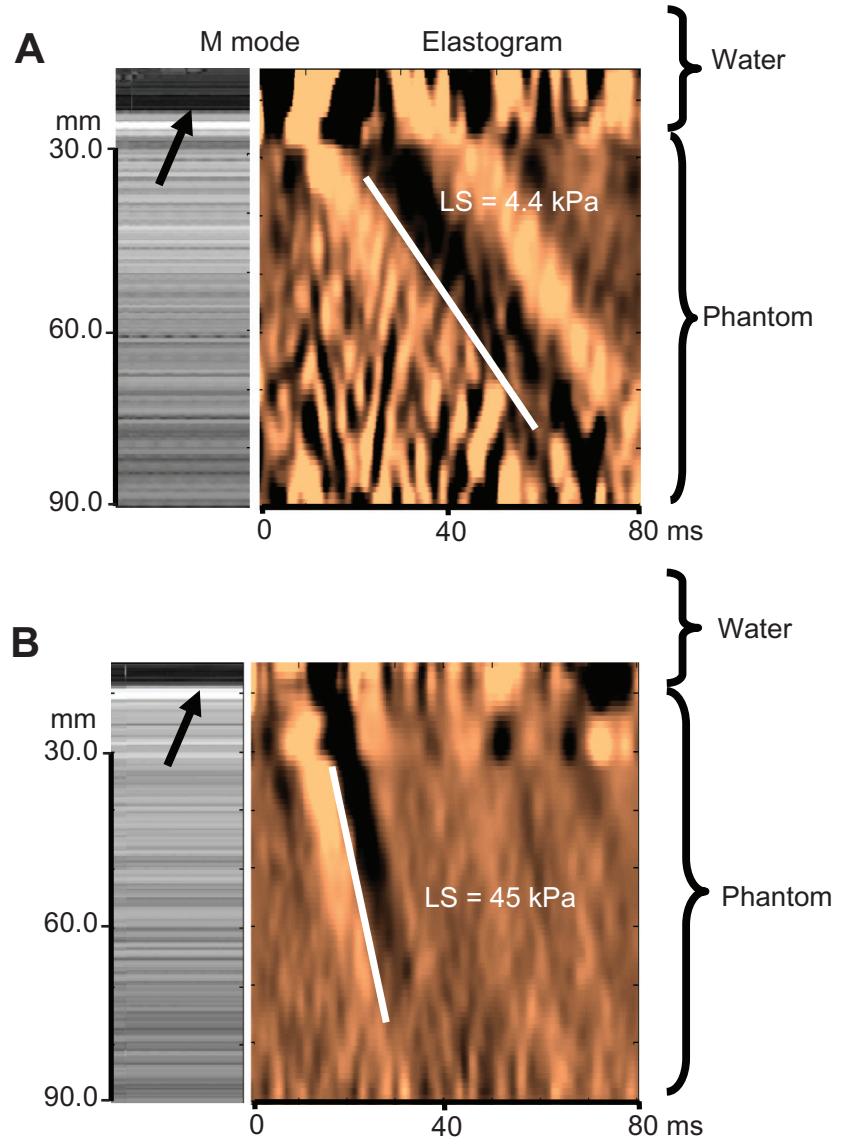

Figure 2 Shear wave propagation and stiffness measurements in liver-mimicking copolymer phantoms surrounded by water. Representative $M$ mode image and elastogram with shear wave propagation is shown in liver-ascites mimicking copolymer-in-oil phantoms surrounded by $20 \mathrm{~mm}$ water (arrow) using stiffness of (A) $4.8 \mathrm{kPa}$ and (B) $40 \mathrm{kPa}$.

Notes: Clear shear wave formation can be seen despite the presence of water, which corresponds well to the phantom stiffness obtained without ascites. Some wave reflections can be seen in the water phase in the upper panel. Standard deviation was less than $10 \%$ for all phantoms after 10 measurements.

Abbreviation: LS, liver stiffness.

\section{Transient elastography ( $\mathrm{XL}$ probe) identifies nonhepatic causes of ascites}

Altogether, a series of 24 patients with ascites of different origin were then studied with both the M and the XL probe. Liver stiffness could be measured in 23 of the 24 patients with the XL probe $(95.8 \%)$. Interestingly, 11 patients $(45.8 \%)$ were also measurable using the conventional $\mathrm{M}$ probe. As shown in Figure 4, all six patients (24\%) with noncirrhotic ascites had almost normal liver stiffness of $<8 \mathrm{kPa}$. Two patients had portal vein thrombosis, one had biliary pancreatitis, and three had peritoneal carcinomatosis originating from ovarian cancer without liver metastasis. The remaining 18 patients had a liver stiffness $>30 \mathrm{kPa}$. In all of these patients, a hepatic cause was established. The majority of patients $(72 \%)$ had decompensated liver cirrhosis which was due to alcoholic liver disease except for 


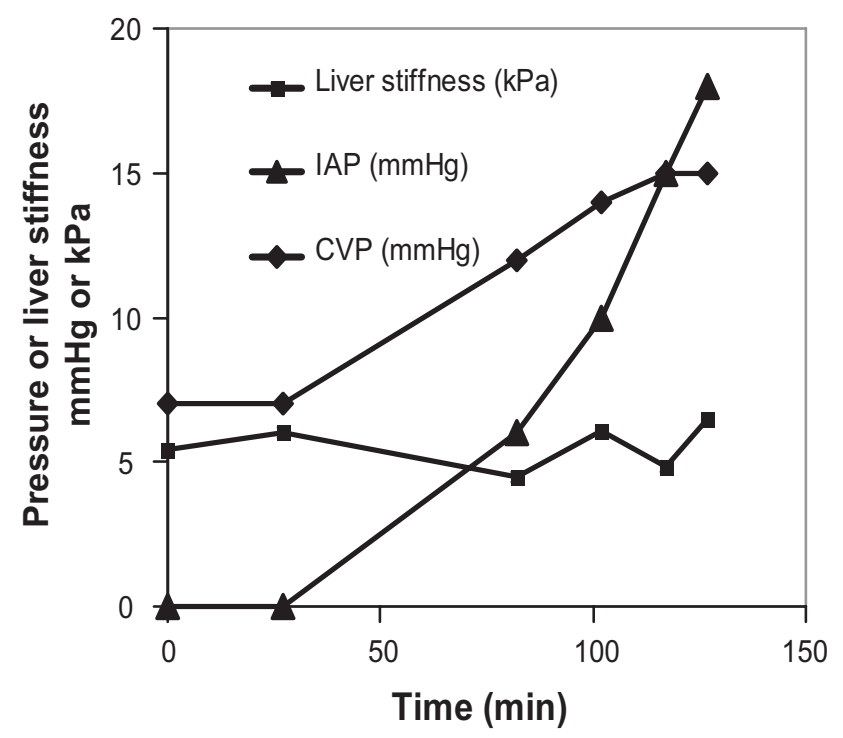

Figure 3 Elevation of intra-abdominal pressure does not increase liver stiffness in an animal model of ascites.

Notes: Using a laparoscopic trocar in narcotized German landrace pigs, isotonic saline solution was installed to generate artificial ascites and to modulate the intraabdominal pressure up to $18 \mathrm{mmHg}$. LS remained normal despite increased intraabdominal pressure. Note that central venous pressure also increased over time to prevent compression of central veins and to maintain blood circulation. LS of each time point is the result of 10 measurements. The interquartile range was less than $30 \%$ in all measurements. The figure is a representative of three independent experiments.

Abbreviations: LS, liver stiffness; IAP, intra abdominal pressure; CVP, central venous pressure.

one case with hepatitis virus $\mathrm{C}$ infection and $\alpha 1$-antitrypsin deficiency. Two patients had cardiac cirrhosis (patients 7 and 8) with manifest liver congestion due to longstanding coronary heart disease. One patient had extramedullary hematopoiesis after long-lasting myelofibrosis with a massively enlarged spleen (patient 22). Two patients $(8.3 \%$, patients 23 and 24) had liver metastasis and in one case additional obstructive cholestasis. In conclusion, a low liver stiffness $<8 \mathrm{kPa}$ excludes a hepatic cause of ascites, while a liver stiffness $>30 \mathrm{kPa}$ is highly suggestive of liver disease, ie, cirrhosis.

\section{Discussion}

In this work we have shown that liver stiffness can be accurately assessed by transient elastography using the more powerful XL probe despite the presence of ascites. In particular, we demonstrate that a transient elastography-generated shear wave is not altered in a copolymer phantom by surrounding ascites, ascites and increased intra-abdominal pressure do not increase liver stiffness using an animal ascites model, and liver stiffness seems to be almost normal in patients with nonhepatic causes of ascites. Thus, transient elastography (XL probe) could be used as an early diagnostic tool for rapid identification of nonhepatic causes of ascites similar to previous studies using acoustic radiation force impulse and real-time tissue elastography.

Our study is the first to demonstrate that ascites should no longer be regarded as an exclusion criterion for transient elastography. This is especially relevant given that transient elastography is generally considered a reference method with regard to liver cirrhosis. ${ }^{12,13}$ Moreover, we show on phantom polymers that a surrounding liquid layer does not alter liver stiffness measurements as long as the probe is perpendicularly directed towards the phantom. Most notably, we also demonstrate evidence in a large animal ascites model that increased intra-abdominal pressure does not affect liver stiffness. Occasionally encountered transient increases of liver stiffness during filling of the abdominal cave were due to compression of the low-pressure central veins, as has been described previously. ${ }^{21,23}$

It is surprising that transient elastography was able to measure liver stiffness through an ascites lamella of up to $39 \mathrm{~mm}$. Only one patient with end-stage alcoholic liver cirrhosis and an ascites lamella of $24 \mathrm{~mm}$ could not be measured. Criteria for valid measurements require a success rate of $>60 \%$ and an interquartile range $<30 \%$. In $75 \%$ of the patients, including all patients with non-hepatic ascites, valid measurements were possible. In five patients (20.8\%), those criteria were not met. However, in almost all of these patients, liver stiffness was either very high at $75 \mathrm{kPa}$ or the interquartile range did not exceed $40 \%$. In addition, liver morphology as determined by ultrasound, showed definite signs of cirrhosis. The only patient with a very high and unacceptable interquartile range of $70 \%$ had liver metastasis that is known to increase liver stiffness. ${ }^{13}$

Our study confirms two recent reports recommending use of liver stiffness to discriminate between cirrhotic and noncirrhotic ascites. ${ }^{14,15}$ In the first study, Hirooka et al ${ }^{15}$ applied real-time elastography to patients with artificial ascites installed for radiofrequency ablation. They showed that liver stiffness does not depend on the presence of ascites. The recent larger study by Bota et $\mathrm{al}^{14}$ in 139 patients with various causes of ascites showed that acoustic radiation force impulse was able to discriminate between cirrhotic and noncirrhotic ascites in $>95 \%$ of cases. Only $4.5 \%$ of patients were incorrectly classified.

In general, we noticed two differences with respect to the study by Bota et al. First, the liver stiffness-discriminating gap between patients with hepatic and nonhepatic ascites seems to be larger in transient elastography as compared with acoustic radiation force impulse (3.0 versus $1.45 \mathrm{~m} / \mathrm{sec}$ 


\section{Etiology of ascites}

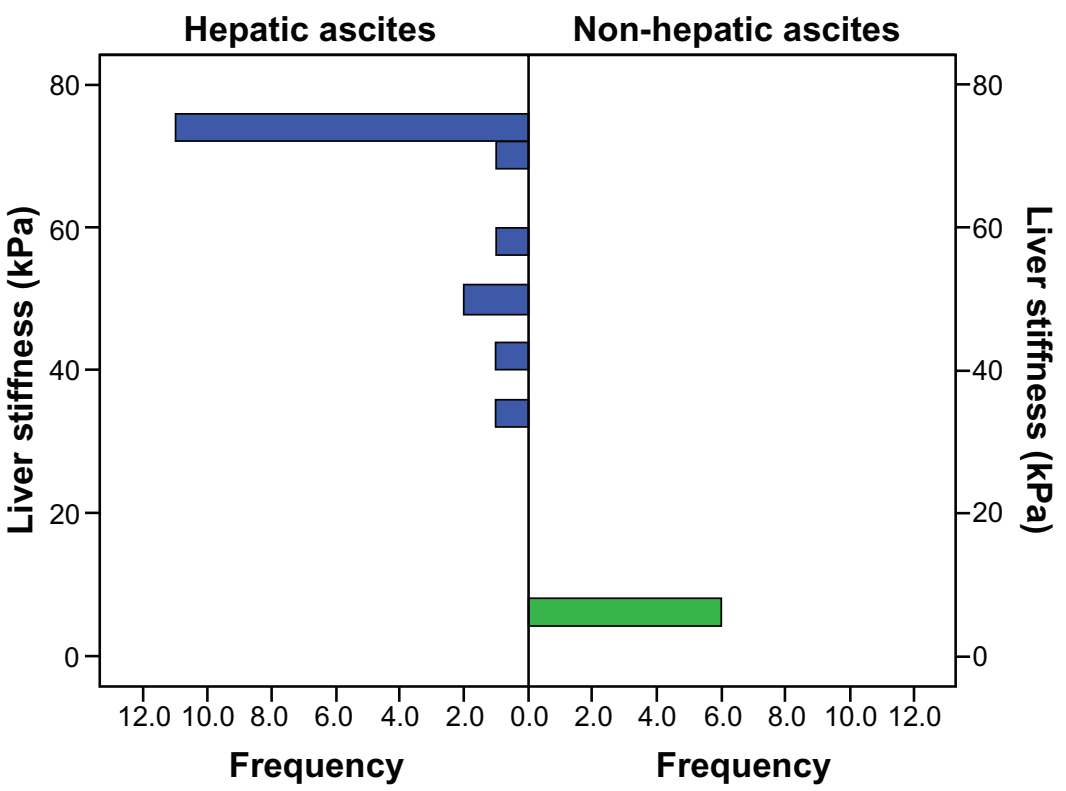

Figure 4 Distribution of liver stiffness in 23 patients with hepatic and nonhepatic ascites. Note: The corresponding interquartile range is shown in Table 2.

in acoustic radiation force impulse as compared with transient elastography with 66.2 versus $5.4 \mathrm{kPa}$ ). This gap could not be explained by the different units. If shear wave velocity (V) as measured by acoustic radiation force impulse was transformed to stiffness ( $\mathrm{E}=$ Young's modulus) in $\mathrm{kPa}$ using the formula $\mathrm{E}=3 \rho \mathrm{V}^{2}$ the gap was still smaller (27 $\mathrm{kPa}$ versus $6.3 \mathrm{kPa}$ ). Of course, patient differences could generally explain these differences. However, it is also very likely that the recently proposed diagnostic algorithm for transient elastography contributed to the better outcome of transient elastography in our study. ${ }^{13}$ This new algorithm includes a timely determination of glutamate oxaloacetate transaminase levels within one day to estimate the degree of hepatic inflammation. In addition, a routine abdominal ultrasound is performed before each transient elastography, to exclude potential interferences, such as congestion, cholestasis, or nodular hepatic masses. ${ }^{13}$ This algorithm allows a more individualized interpretation of liver stiffness. ${ }^{13}$ This is based on our recent findings that, in addition to inflammation, ${ }^{24,25}$ hepatic congestion ${ }^{21}$ and mechanic cholestasis $^{20}$ can drastically increase liver stiffness independent of fibrosis stage. Indeed, we identified one patient with additional mechanical cholestasis and two patients with hepatic congestion.

Second, we explicitly use the term "nonhepatic" instead of "noncirrhotic" because other noncirrhotic liver pathologies, such as congestion, tumor infiltration, or liver metastasis, may also lead to portal hypertension, ascites, and increased liver stiffness independent of fibrosis stage. In this context, it is important to bear in mind that a liver stiffness $<8 \mathrm{kPa}$ has a very high negative predictive values to rule out chronic liver disease. ${ }^{12,13}$ Thus, once liver stiffness measurements in a patient with ascites are valid and below $8 \mathrm{kPa}$, hepatic ascites is excluded almost with certainty. In contrast, an increased liver stiffness may be due to causes other than cirrhosis or in combination with cirrhosis. Therefore, we suggest that increased liver stiffness should be interpreted with caution in the context of other clinical, ultrasound, and laboratory findings. In addition, potential interventions should be considered, such as treatment with diuretics or alcohol detoxification, to unmask other causes of increased liver stiffness, such as congestion or inflammation..$^{3,21}$

\section{Conclusion}

In this work we have demonstrated that transient elastography is an excellent first-line tool for patients with newly developed ascites. It enables exclusion of liver cirrhosis or other hepatic causes on the first day of admission in cases of liver stiffness less than $8 \mathrm{kPa}$. Prejudgments that often unnecessarily postpone alternative diagnostic measures and initiation of therapies can be avoided. In contrast, an increased liver stiffness $>30 \mathrm{kPa}$ is highly suggestive of manifest liver cirrhosis. It requires further careful clinical, laboratory, endoscopic, or imaging examinations because 
other rare causes, such as liver metastasis or extramedullar hematopoiesis, may be present in addition to cirrhosis.

\section{Acknowledgment}

This study was supported by the Dietmar Hopp and the Manfred Lautenschläger Foundation. GM is the recipient of an Olympia-Morata-Fellowship from University of Heidelberg.

\section{Disclosure}

CB and LS are employees in the Research and Development Department of Echosens, the manufacturer of FibroScan.

\section{References}

1. Runyon BA. Care of patients with ascites. N Engl J Med. 1994;330(5): 337-342.

2. Naveau S, Perlemuter G, Balian A. Epidemiology and natural history of cirrhosis. Rev Prat. 2005;55(14):1527-1532. French.

3. Mueller S, Millonig G, Sarovska L, et al. Increased liver stiffness in alcoholic liver disease: differentiating fibrosis from steatohepatitis. World J Gastroenterol. 2010;16(8):966-972.

4. Di Lelio A, Cestari C, Lomazzi A, Beretta L. Cirrhosis: diagnosis with sonographic study of the liver surface. Radiology. 1989;172(2): 389-392.

5. Runyon BA, Montano AA, Akriviadis EA, Antillon MR, Irving MA, McHutchison JG. The serum-ascites albumin gradient is superior to the exudate-transudate concept in the differential diagnosis of ascites. Ann Intern Med. 1992;117(3):215-220.

6. Bravo AA, Sheth SG, Chopra S. Liver biopsy. $N$ Engl J Med. 2001;344(7):495-500

7. Abdi W, Millan JC, Mezey E. Sampling variability on percutaneous liver biopsy. Arch Intern Med. 1979;139(6):667-669.

8. Bedossa P, Dargere D, Paradis V. Sampling variability of liver fibrosis in chronic hepatitis C. Hepatology. 2003;38(6):1449-1457.

9. Cadranel JF, Rufat P, Degos F. Practices of liver biopsy in France: results of a prospective nationwide survey. For the Group of Epidemiology of the French Association for the Study of the Liver (AFEF). Hepatology. 2000;32(3):477-481.

10. Maharaj B, Maharaj RJ, Leary WP, et al. Sampling variability and its influence on the diagnostic yield of percutaneous needle biopsy of the liver. Lancet. 1986;1(8480):523-525.
11. Regev A, Berho M, Jeffers LJ, et al. Sampling error and intraobserver variation in liver biopsy in patients with chronic HCV infection. Am J Gastroenterol. 2002;97(10):2614-2618.

12. Castera L, Pinzani M. Biopsy and non-invasive methods for the diagnosis of liver fibrosis: does it take two to tango? Gut. 2010;59(7):861-866.

13. Mueller S, Sandrin L. Liver stiffness: a novel parameter for the diagnosis of liver disease Hepatic Medicine: Evidence and Research. 2010;2:49-67.

14. Bota S, Sporea I, Sirli R, Popescu A, Danila M, Sendroiu M. Value of acoustic radiation force impulse elastography for the assessment of ascites syndrome. World J Radiol. 2011;3(8):205-209.

15. Hirooka M, Koizumi Y, Hiasa Y, et al. Hepatic elasticity in patients with ascites: evaluation with real-time tissue elastography. AJR Am J Roentgenol. 2011;196(6):W766-W771.

16. Muller M, Gennisson JL, Deffieux T, Tanter M, Fink M. Quantitative viscoelasticity mapping of human liver using supersonic shear imaging: preliminary in vivo feasibility study. Ultrasound Med Biol. 2009;35(2):219-229.

17. Sandrin L, Fourquet B, Hasquenoph JM, et al. Transient elastography: a new noninvasive method for assessment of hepatic fibrosis. Ultrasound Med Biol. 2003;29(12):1705-1713.

18. de Ledinghen V, Vergniol J, Foucher J, El-Hajbi F, Merrouche W, Rigalleau V. Feasibility of liver transient elastography with FibroScan using a new probe for obese patients. Liver Int. 2010;30(7):1043-1048.

19. Oudry J, Bastard C, Miette V, Willinger R, Sandrin L. Copolymerin-oil phantom materials for elastography. Ultrasound Med Biol. 2009;35(7):1185-1197.

20. Millonig G, Reimann FM, Friedrich S, et al. Extrahepatic cholestasis increases liver stiffness (FibroScan) irrespective of fibrosis. Hepatology. 2008;48(5):1718-1723.

21. Millonig G, Friedrich S, Adolf S, et al. Liver stiffness is directly influenced by central venous pressure. J Hepatol. 2010;52(2):206-210.

22. Zink J, Greenway CV. Control of ascites absorption in anesthetized cats: effects of intraperitoneal pressure, protein, and furosemide diuresis. Gastroenterology. 1977;73(5):1119-1124.

23. Zink J, Greenway CV. Intraperitoneal pressure in formation and reabsorption of ascites in cats. Am J Physiol. 1977;233(2):H185-H190.

24. Sagir A, Erhardt A, Schmitt M, Haussinger D. Transient elastography is unreliable for detection of cirrhosis in patients with acute liver damage. Hepatology. 2008;47(2):592-595.

25. Arena U, Vizzutti F, Corti G, et al. Acute viral hepatitis increases liver stiffness values measured by transient elastography. Hepatology. 2008;47(2):380-384.
Hepatic Medicine: Evidence and Research

\section{Publish your work in this journal}

Hepatic Medicine: Evidence and Research is an international, peerreviewed, open access journal covering all aspects of adult and pediatric hepatology in the clinic and laboratory including the following topics: Pathology, pathophysiology of hepatic disease; Investigation and treatment of hepatic disease; Pharmacology of drugs used for

\section{Dovepress}

the treatment of hepatic disease. Issues of patient safety and quality of care will also be considered. The manuscript management system is completely online and includes a very quick and fair peer-review system, which is all easy to use. Visit http://www.dovepress.com/ testimonials.php to read real quotes from published authors. 